\title{
Clinical practice guidelines for the care and treatment of breast cancer: 16. Locoregional post-mastectomy radiotherapy
}

\author{
Pauline T. Truong, Ivo A. Olivotto, Timothy J. Whelan, Mark Levine, for the Steering Committee \\ on Clinical Practice Guidelines for the Care and Treatment of Breast Cancer
}

A patient version of these guidelines appears in Appendix 1.

Abstract

Objective: To provide information and recommendations to assist women with breast cancer and their physicians in making decisions regarding the use of locoregional post-mastectomy radiotherapy (PMRT).

Outcomes: Locoregional control, disease-free survival, overall survival and treatment-related toxicities.

Evidence: This guideline is based on a review of all meta-analyses, consensus statements and other guidelines published between 1966 and November 2002. Searches of MEDLINE and CANCERLIT for English-language randomized controlled trials published between 1995 and November 2002 were also conducted to supplement the literature previously reviewed by the American Society of Clinical Oncology (ASCO) Health Services Research Committee panel in its published guideline. A nonsystematic review of the literature was continued through June 2003.

Recommendations:

- Locoregional PMRT is recommended for women with an advanced primary tumour (tumour size $5 \mathrm{~cm}$ or greater, or tumour invasion of the skin, pectoral muscle or chest wall).

- Locoregional PMRT is recommended for women with 4 or more positive axillary lymph nodes.

- The role of PMRT in women with 1 to 3 positive axillary lymph nodes is unclear. These women should be offered the opportunity to participate in clinical trials of PMRT.

- Locoregional PMRT is generally not recommended for women who have tumours that are less than $5 \mathrm{~cm}$ in diameter and who have negative axillary nodes.

- Other patient, tumour and treatment characteristics, including age, histologic grade, lymphovascular invasion, hormone receptor status, number of axillary nodes removed, axillary extracapsular extension and surgical margin status, may affect locoregional control, but their use in specifying additional indications for PMRT is currently unclear.

- PMRT should encompass the chest wall and the supraclavicular, infraclavicular and axillary apical lymph node areas.

- To reduce the risk of lymphedema, radiation of the entire axilla should not be used routinely after complete axillary dissection of level I and II lymph nodes.

- A definite recommendation regarding the inclusion of the internal mammary lymph nodes in PMRT cannot be made because of limited and inconsistent data.
- The use of modern techniques in radiotherapy planning is recommended to minimize excessive normal tissue exposure, particularly to the cardiac and pulmonary structures.

- Common short-term side effects of PMRT, including fatigue and skin erythema, are generally tolerable and not dose-limiting. Severe long-term side effects, including lymphedema, cardiac and pulmonary toxicities, brachial plexopathy, rib fractures and secondary neoplasms, are relatively rare.

- The optimal sequencing of PMRT and systemic therapy is currently unclear. Regimens containing anthracyclines or taxanes should not be administered concurrently with radiotherapy because of the potential for increased toxicity.

Validation: The authors' original text was submitted for review, revision and approval by the Steering Committee on Clinical Practice Guidelines for the Care and Treatment of Breast Cancer. Subsequently, feedback was provided by 11 oncologists from across Canada. The final document was approved by the steering committee.

Sponsor: The Steering Committee on Clinical Practice Guidelines for the Care and Treatment of Breast Cancer was convened by Health Canada.

Completion date: November 2003.

CMAJ 2004;170(8):1263-73

$\mathrm{S}$ tandard primary surgical treatment options for women with invasive breast cancer include breast-conserving surgery or mastectomy. Post-mastectomy radiotherapy (PMRT), which generally includes radiation of the chest wall and regional lymph nodes, has been demonstrated in randomized controlled trials (RCTs) to improve locoregional control in patients with breast cancer. ${ }^{1-7}$ The impact of PMRT on breast-cancer-specific survival and overall survival is less well defined. Until recent years, trials had not demonstrated improved survival with PMRT compared with surgery alone when no systemic therapy was used. ${ }^{1-4}$ Since 1980, the indications for systemic therapy for breast cancer have evolved, with increased use of chemotherapy and hormone therapy in the adjuvant setting. ${ }^{89}$ In 1997, 2 randomized trials were published, demonstrating that PMRT improved overall survival as well as locoregional control among premenopausal node-positive patients treated with chemotherapy. ${ }^{5,6}$ In 1999, similar improve- 
ments in locoregional control and survival were demonstrated with PMRT in a trial involving postmenopausal node-positive patients who received tamoxifen. ${ }^{7}$ The results of these 3 trials have sparked considerable debate and prompted the publication of a number of editorials, consensus statements and treatment guidelines addressing the role of PMRT in breast cancer management. ${ }^{10-16}$

\section{Methods}

This guideline is based on a review of all meta-analyses, consensus statements and other treatment guidelines published between 1966 and November 2002. Searches of MEDLINE and CANCERLIT for English-language randomized controlled trials published between 1995 and November 2002 were also conducted to supplement the literature previously reviewed by the American Society of Clinical Oncology (ASCO) Health Services Research Committee panel in its published guideline. ${ }^{10}$

Search terms included the following: "breast," "breast neoplasms," "mastectomy," "radiotherapy" and "locoregional radiotherapy." A nonsystematic review of the literature was continued through June 2003. Additional data were identified by reviewing references in review papers, textbooks, other guidelines and consensus statements.

The outcomes evaluated were locoregional control, diseasefree survival, overall survival and treatment-related toxicities.

The quality of the evidence on which recommendations are based was categorized into 5 levels. ${ }^{17}$ The iterative process used to develop this guideline has been described previously. ${ }^{18}$ An initial draft of this guideline was reviewed by members of the Steering Committee for Clinical Practice Guidelines for the Care and Treatment of Breast Cancer. A subsequent draft was sent to 11 expert oncologists across Canada for their feedback. The final document was approved by the steering committee.

Our method of performing a systematic review and ranking available evidence resulted in recommendations similar to those of ASCO. ${ }^{10} \mathrm{~A}$ distinction between the present guideline and the ASCO guideline is the difference in emphasis on subgroups. We considered subgroup data whenever it was available. However, in contrast to the ASCO process, we focused less on results from small subgroups, since definitive recommendations cannot be based on such data. We placed more weight on the generalizability of results of available data and presented the information regarding these trials in the context of modern clinical settings. The ASCO guideline was published in 2001; hence, our guideline is based on more up-to-date data.

Our guideline is much more comprehensive than the 1-page consensus statement by Harris and colleagues. ${ }^{13}$ We describe trial data in detail, and the rationale behind our recommendations is explicit. Finally, our process aimed to establish consensus among Canadian oncologists and thus achieve "Canadian ownership," an important step to enhance the likelihood of guideline adoption and implementation.

\section{Evidence for post-mastectomy radiotherapy}

Meta-analyses and RCTs of locoregional PMRT have consistently demonstrated that PMRT reduces the risk of locoregional failure to the chest wall and regional lymphatic drainage sites, including the ipsilateral axillary, supr- aclavicular and infraclavicular and internal mammary nodes

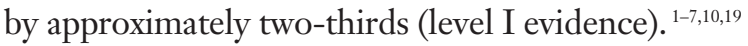

The effects of PMRT on breast-cancer-specific and overall survival have been less clear. An overview analysis of 8 RCTs, conducted before the era of adjuvant systemic therapy, in which 7941 women were randomly allocated to receive adjuvant PMRT or observation after simple or radical mastectomy reported no differences in survival in the first 10 years of follow-up. ${ }^{1}$ Beyond 10 years, a significant excess of deaths due to cardiovascular causes was observed among patients in the PMRT group, but this was counterbalanced by a reduction of deaths due to breast cancer. ${ }^{1}$ A re-analysis revealed no significant differences in overall mortality with longer follow-up. ${ }^{2}$

Two meta-analyses from the Early Breast Cancer Trialists' Collaborative Group (EBCTCG) of RCTs that compared local therapies in 20000 women with early breast cancer demonstrated that radiotherapy provided improved locoregional control but showed no improvement in overall survival compared with surgery alone., ${ }^{3,4}$ Radiotherapy reduced the risk of locoregional failure at 10 years of followup $(27.2 \%$ v. $8.8 \%, 2 p<0.00001)$ and at 20 years of followup $(30.1 \%$ v. $10.4 \%, 2 p<0.00001) .{ }^{4}$ Significant differences in overall survival with the use of radiotherapy were not demonstrated at the 10 -year follow-up $(54.5 \%$ in the control group and $56.6 \%$ in the radiotherapy group) or at the 20 -year follow-up $35.9 \%$ in the control group and $37.1 \%$ in the radiotherapy group, $2 p=0.06) .{ }^{4}$ However, at 20 years, radiotherapy was associated with significant reductions in deaths related to breast cancer, which were offset by increases in deaths from other causes, ${ }^{4}$ especially vascular causes (death rate ratio 1.30, $p=0.0007$ ) (level I evidence). ${ }^{3,4}$

Difficulties arise when attempting to interpret the results of the 2 EBCTCG overviews in the context of modern oncologic practice. The overviews combined studies that used diverse surgical treatments (including breast-conserving surgery, simple mastectomy, modified radical mastectomy and radical mastectomy), systemic therapies (many trials used no systemic therapy) and radiotherapy techniques and doses (several trials did not include the chest wall; some trials delivered high doses to the heart when treating the internal mammary nodes; and several older trials used orthovoltage equipment and low doses of radiotherapy). Applying the results of these overviews to form the basis for current treatment guidelines for PMRT in modern practice is thus problematic.

A meta-analysis restricted to patients receiving systemic therapy included data from 18 RCTs published between 1967 and $1999 .{ }^{19}$ The majority of the trials included pre- and postmenopausal women with node-positive disease who underwent modified radical mastectomy. ${ }^{5-7,20-37}$ The adjuvant chemotherapy regimen most commonly used was cyclophosphamide, methotrexate and fluorouracil (CMF). The median duration of follow-up was 7.5-14.5 years. In this meta-analysis, locoregional radiotherapy reduced the risks of any recurrence (odds ratio $[\mathrm{OR}] 0.69,95 \%$ confidence interval $[\mathrm{CI}]$ $0.58-0.83, p=0.00004)$, locoregional failure (OR $0.25,95 \%$ 
CI $0.19-0.34, p<0.000001)$ and mortality (OR $0.83,95 \%$ CI $0.74-0.94, p=0.004$ ) (level I evidence). ${ }^{19}$

The ASCO guideline, published in March 2001, examined 18 randomized trials that compared systemic therapy plus PMRT with systemic therapy alone in over 6300 patients. ${ }^{10}$ The British Columbia and Danish trials provide the strongest evidence from individual trials that PMRT improves diseasefree survival and overall survival (level I evidence)..$^{5-7}$

The British Columbia trial compared PMRT and CMF chemotherapy with CMF chemotherapy alone in premenopausal women with node-positive breast cancer. ${ }^{6}$ It showed a $56 \%$ reduction in locoregional failure (relative risk [RR] 0.44, 95\% CI 0.26-0.77, $p=0.003$ ), a 29\% reduction in breast cancer mortality (RR $0.71,95 \%$ CI $0.51-0.99, p=0.05)$ and a $26 \%$ reduction in overall mortality (RR $0.74,95 \%$ CI $0.53-1.02, p=0.07$ ) at 15 years. The update of this trial reported a $30 \%$ reduction in overall mortality (RR 0.70, $p=0.02) .^{38}$

The Danish 82b study compared PMRT and CMF chemotherapy with the same chemotherapy alone in premenopausal patients. ${ }^{5}$ It reported reductions in locoregional failure ( $9 \%$ v. $32 \%, p<0.001)$ and improved 10 -year diseasefree survival $(48 \%$ v. $34 \%, p<0.001)$ and overall survival $(54 \%$ v. $45 \%, p<0.001)$ with the use of PMRT. The Danish 82c study compared PMRT and tamoxifen with tamoxifen alone in postmenopausal patients. It similarly reported reductions in locoregional failure ( $8 \%$ v. $35 \%, p<0.001)$, and improved disease-free survival ( $36 \%$ v. $24 \%, p<0.001)$ and overall survival $(45 \%$ v. $36 \%, p=0.03)$ with PMRT.

In summary, RCTs and meta-analyses have consistently demonstrated that PMRT improves locoregional control in women with node-positive breast cancer (level I evidence). The impact of PMRT on survival is less clearly defined. Although the data pertaining to survival with PMRT are less consistent than those pertaining to locoregional control with PMRT, 3 large trials ${ }^{5-7}$ and a meta-analysis ${ }^{19}$ have demonstrated that PMRT improves disease-free and overall survival among women treated with systemic therapy (level I evidence). This survival benefit supports the hypothesis that, among women with breast cancer at high risk of locoregional recurrence, systemic therapy reduces distant micrometastasis and thus allows the effects of PMRT in reducing locoregional tumour burden to enhance disease control and survival. ${ }^{5-7,11,19}$

\section{Limitations of the evidence}

Before the publication of the British Columbia trial and the 2 Danish trials in 1997, PMRT practice across Canada varied from no locoregional radiation to radiation for selected subgroups of patients. The results of these 3 trials prompted many radiation oncologists to re-examine their practices, and much discussion ensued.

One of the issues that has been raised is the generalizability of these trials to current clinical practice. Some have felt that the rate of locoregional failure in all 3 trials was substantially higher than that currently observed..$^{12,39-41}$ The high risk of local failure has been attributed to the limited axillary dissection performed (median number of axillary nodes removed was 7 in the Danish trials and 11 in the British Columbia trial). As well, in the Danish 82c trial, 1 year of tamoxifen therapy was used, as opposed to the current standard of 5 years of tamoxifen therapy. In the Danish $82 \mathrm{~b}$ trial and the British Columbia trial, CMF chemotherapy was used, ${ }^{5,6}$ as opposed to anthracycline chemotherapy currently in common use. ${ }^{42}$

A potential limitation of PMRT is long-term toxicity, particularly cardiotoxicity, a risk that may be increased with the use of radiotherapy in conjunction with chemotherapy regimens including anthracyclines and taxanes. ${ }^{43-46}$ The potential detrimental late effects of combined PMRT and these systemic therapy agents remain unknown.

Consequently, many oncologists are concerned that the additional survival benefits afforded by PMRT in patients treated with modern surgical techniques and adjuvant systemic therapy are unclear and currently reserve PMRT for patients deemed at highest risk of locoregional recurrence on the basis of an advanced primary tumour or 4 or more positive axillary nodes. These patients are most likely to benefit from the prevention of locoregional recurrence. Accordingly, the risk of long-term toxicity is outweighed by the avoidance of recurrence and the potential for improved survival.

\section{Recommendations (including evidence and rationale)}

- Locoregional PMRT is recommended for women with an advanced primary tumour (tumour size 5 $\mathrm{cm}$ or greater, or tumour invasion of the skin, pectoral muscle or chest wall).

- Locoregional PMRT is recommended for women with 4 or more positive axillary lymph nodes.

- The role of PMRT in women with 1 to 3 positive axillary lymph nodes is unclear. These women should be offered the opportunity to participate in clinical trials of PMRT.

In the Danish $82 \mathrm{~b}$ study involving premenopausal women receiving CMF chemotherapy, among the $234 \mathrm{pa}-$ tients who had a tumour greater than $5 \mathrm{~cm}$ in diameter, PMRT was associated with a reduction in the locoregional failure rate $(12 \%$ v. $42 \%)$ and an improved 10 -year overall survival rate (40\% v. $33 \%)$ (level II evidence, $p$ value not stated). ${ }^{5}$ In the Danish 82c study involving postmenopausal patients receiving tamoxifen, among patients who had a tumour greater than $5 \mathrm{~cm}$ in diameter $(n=161)$, deep fascia invasion $(n=206)$ or skin invasion $(n=189)$, the addition of PMRT reduced locoregional failure rates from $34 \%$ to $10 \%, 45 \%$ to $6 \%$ and $34 \%$ to $8 \%$ respectively (level II evidence, $p$ value not stated).

The meta-analyses of PMRT did not report results by 
nodal subgroup. The evidence for determining patients at highest risk of locoregional recurrence is therefore based on subgroup analyses of individual randomized trials of PMRT and on multivariate analyses of patients enrolled in prospective cohort studies. Table 1 summarizes results for locoregional failure and overall survival by nodal status in 6 randomized trials. In terms of locoregional failure, all trials showed a trend in favour of PMRT in all subgroups according to nodal status. In both the British Columbia trial ${ }^{38}$ and the Dana Farber trial, ${ }^{28}$ there was a statistically significant difference in locoregional failure rates reported among women with 4 or more positive nodes. In terms of overall survival, the Glasgow trial ${ }^{29}$ reported statistically significant improvement with PMRT $(p=0.01)$. Most other studies that performed statistical analyses within nodal subgroups suggested that PMRT was associated with nonsignificant trends toward improved overall survival..$^{5-7,30,38}$ Only 1 trial reported an opposite trend of reduced overall survival with PMRT. ${ }^{28}$

Analyses of cohorts of patients in randomized trials also support the notion that the presence of 4 or more positive nodes with a tumour is associated with a substantial risk of locoregional failure. Katz and colleagues ${ }^{39,40}$ reported on 1031 patients who participated in 5 trials of anthracycline chemotherapy at the M.D. Anderson Cancer Center. The median follow-up was 116 months. On multivariate analysis, the presence of 4 or more involved axillary nodes, a tumour greater than $5 \mathrm{~cm}$ in diameter, close or positive surgical margins and gross multicentric disease were found to be independent predictors of locoregional failure (all $p<0.01) .^{40}$
Recht and colleagues ${ }^{41}$ reported on 2016 patients in 4 randomized trials conducted by the Eastern Clinical Oncology Group. The median follow-up was 12.1 years. Patients were treated with a variety of systemic regimens, including CMF, CMF plus prednisone and tamoxifen, and anthracycline-based regimens. Tamoxifen was often given for longer than 1 year. Multivariate analysis showed that increasing tumour size, increasing numbers of involved nodes, negative estrogen receptor status, and decreasing number of nodes examined were independent predictors of locoregional failure. The risk of locoregional failure with or without simultaneous distant failure at 10 years was $12.9 \%$ among patients with 1 to 3 positive nodes and $28.7 \%$ among patients with 4 or more positive nodes.

Because of the inconsistencies in the available evidence, the role of PMRT in women with 1 to 3 positive axillary lymph nodes is currently undefined. The proportional reduction by about two-thirds in the locoregional failure rates associated with PMRT is likely of a similar magnitude among women with 1 to 3 positive nodes as it is among women with 4 or more involved nodes. ${ }^{5-7}$ However, the absolute magnitude of reduction would be smaller among women with 1 to 3 involved nodes, since the baseline risk of locoregional failure is lower in this subgroup. Women with 1 to 3 positive axillary nodes should be offered the opportunity to participate in clinical trials designed to study the effects of locoregional radiotherapy. The National Cancer Institute of Canada Clinical Trials Group (NCIC CTG) MA25 study, which randomly assigned patients with 1 to 3

Table 1: Summary of locoregional failure and overall survival rates by nodal status in 6 randomized trials of locoregional postmastectomy radiotherapy (PMRT)

\begin{tabular}{|c|c|c|c|c|c|c|c|c|c|c|c|}
\hline \multirow[b]{2}{*}{ Study } & \multirow[b]{2}{*}{ Chemotherapy } & \multirow{2}{*}{$\begin{array}{l}\text { Median } \\
\text { duration of } \\
\text { follow-up }\end{array}$} & \multirow[b]{2}{*}{ Patients } & \multirow[b]{2}{*}{$\begin{array}{c}\text { No. of } \\
\text { patients }\end{array}$} & \multirow[b]{2}{*}{$\begin{array}{l}\text { Nodal } \\
\text { status }\end{array}$} & \multicolumn{3}{|c|}{ Locoregional failure* } & \multicolumn{3}{|c|}{ Overall survival } \\
\hline & & & & & & PMRT, \% & $\begin{array}{c}\text { No } \\
\text { PMRT, \% }\end{array}$ & $p$ value & PMRT, \% & $\begin{array}{c}\text { No } \\
\text { PMRT, \% }\end{array}$ & $p$ value \\
\hline \multirow{3}{*}{$\begin{array}{l}\text { Overgaard et al } \\
\text { (Danish 82b trial), } \\
1997^{5}\end{array}$} & \multirow[t]{3}{*}{$\mathrm{CMF}$} & \multirow[t]{3}{*}{$114 \mathrm{mo}$} & \multirow[t]{3}{*}{ Premenopausal } & 135 & Negative & 3 & 17 & NR & $82 \dagger$ & $70 \dagger$ & NR \\
\hline & & & & 1061 & 1-3 positive & 7 & 30 & NR & $62 \dagger$ & $54 \dagger$ & NR \\
\hline & & & & 510 & $\geq 4$ positive & 14 & 42 & $N R$ & $32 \dagger$ & $20 \dagger$ & NR \\
\hline \multirow{3}{*}{$\begin{array}{l}\text { Overgaard et al } \\
\text { (Danish 82c trial), } \\
1999^{7}\end{array}$} & \multirow[t]{3}{*}{ Tam } & \multirow[t]{3}{*}{$119 \mathrm{mo}$} & \multirow[t]{3}{*}{ Postmenopausal } & 132 & Negative & 6 & 23 & NR & $56 \dagger$ & $55 \dagger$ & NR \\
\hline & & & & 794 & $1-3$ positive & 6 & 31 & NR & $55+$ & $44 \dagger$ & NR \\
\hline & & & & 448 & $\geq 4$ positive & 11 & 46 & NR & $24+$ & $17 \dagger$ & NR \\
\hline \multirow{2}{*}{$\begin{array}{l}\text { Ragaz et al (British } \\
\text { Columbia trial), } \\
1997,{ }^{6} 1999^{38}\end{array}$} & \multirow[t]{2}{*}{$\mathrm{CMF}$} & \multirow[t]{2}{*}{$150+\mathrm{mo}$} & \multirow[t]{2}{*}{ Premenopausal } & 183 & 1-3 positive & 8 & 20 & 0.066 & $64 \dagger$ & $53 \dagger$ & 0.07 \\
\hline & & & & 112 & $\geq 4$ positive & 17 & 51 & 0.004 & $35 \dagger$ & $28 \dagger$ & 0.20 \\
\hline \multirow{2}{*}{$\begin{array}{l}\text { McArdle et al } \\
\text { (Glasgow trial), } \\
1986^{29}\end{array}$} & \multirow[t]{2}{*}{$\mathrm{CMF}$} & \multirow[t]{2}{*}{$63 \mathrm{mo}$} & \multirow{2}{*}{$\begin{array}{l}\text { Pre- and } \\
\text { postmenopausal }\end{array}$} & 141 & 1-3 positive & NR & NR & NR & $76 \neq$ & $68 \ddagger$ & 0.76 \\
\hline & & & & 72 & $\geq 4$ positive & NR & NR & NR & $54 \ddagger$ & $46 \ddagger$ & 0.01 \\
\hline $\begin{array}{l}\text { Vélez-Garcia et al } \\
\text { (SECSG trial), } 1992^{30}\end{array}$ & $\mathrm{CMF}$ & $120 \mathrm{mo}$ & $\begin{array}{l}\text { Pre- and } \\
\text { postmenopausal }\end{array}$ & 270 & $\geq 4$ positive & 13 & 25 & 0.067 & $55^{*}$ & $46^{*}$ & NR \\
\hline \multirow{2}{*}{$\begin{array}{l}\text { Griem et al (Dana } \\
\text { Farber trial), } 1987^{28}\end{array}$} & $\mathrm{CMF}$ or $\mathrm{MF}$ & $53 \mathrm{mo}$ & \multirow{2}{*}{$\begin{array}{l}\text { Pre- and } \\
\text { postmenopausal }\end{array}$} & 83 & 1-3 positive & 2 & 5 & 0.61 & $77 \ddagger$ & $85 \ddagger$ & 0.39 \\
\hline & $\mathrm{CA}$ & $45 \mathrm{mo}$ & & 123 & $\geq 4$ positive & 6 & 20 & 0.03 & $59 \neq$ & $63 \ddagger$ & 0.27 \\
\hline
\end{tabular}

Note: SECSG = South-Eastern Cancer Study Group, NR = not reported, $C=$ cyclophosphamide, $M=$ methotrexate, $F=$ fluorouracil, $A=$ adriamycin, Tam $=$ tamoxifen

*Cumulative proportion.

+10-year actuarial survival estimate.

$\ddagger 5$-year actuarial survival estimate. 
positive nodes to receive either locoregional radiotherapy or no radiotherapy after mastectomy, was closed because of lack of accrual. Thus, it is unlikely that data from a randomized trial will be available to directly address the question of PMRT in women with 1 to 3 positive nodes. In the NCIC CTG MA20 study currently underway, women who have undergone breast-conserving surgery and who have nodepositive disease or have node-negative disease and are at high risk of systemic recurrence are randomly allocated to receive standard breast radiotherapy versus locoregional radiotherapy. This study, which stratifies patients according to the number of involved nodes, may provide additional evidence on the role of locoregional radiotherapy in the subgroup of women with 1 to 3 positive nodes.

\section{- Locoregional PMRT is generally not recom-} mended for women who have tumours that are less than $5 \mathrm{~cm}$ in diameter and who have negative axillary nodes.

In the older meta-analyses of trials of PMRT that included women who had tumours less than $5 \mathrm{~cm}$ in diameter and who had node-negative disease, the small absolute improvement in local disease control with PMRT was outweighed by significantly increased risks of vascular-related deaths. ${ }^{1,2}$ In the EBCTCG meta-analysis, although PMRT reduced locoregional failure rates among patients who had node-negative disease, the baseline risk of locoregional failure was relatively low even without PMRT (2.7\% with PMRT v. 9.2\% without PMRT, $2 p<0.00001) .{ }^{4}$ The 25 -year update of the National Surgical Adjuvant Breast and Bowel Project (NSABP) B-04 study provided additional data on the risk of locoregional failure among women who had node-negative disease treated with mastectomy alone. ${ }^{47,48}$ In this study, women who had clinically node-negative disease were randomly allocated to receive radical mastectomy alone, total mastectomy without axillary dissection but with PMRT, or total mastectomy with subsequent axillary dissection if the nodes became positive. At 25 years, $5 \%$ of the patients in the radical mastectomy group experienced local recurrence, as compared with $7 \%$ of those in the total mastectomy group and $1 \%$ in the total mastectomy plus PMRT group. The corresponding data for regional recurrence were $4 \%, 6 \%$ and $4 \%$. When the cumulative incidence of local or regional recurrence was compared between the 3 treatment groups, the $p$ value was 0.002 . Although PMRT reduced the local and regional failure rates, the absolute improvements were small and there was no survival benefit (level I evidence). ${ }^{48}$ Based on the low baseline risk of locoregional failure and the small absolute improvement in locoregional control with the addition of PMRT for small tumours and node-negative disease, contemporary trials of PMRT, ${ }^{5-7}$ including the NCIC CTG MA20 trial, have not included women with these low-risk characteristics.

- Other patient, tumour and treatment characteristics, including age, histologic grade, lymphovascu- lar invasion, hormone receptor status, number of axillary nodes removed, axillary extracapsular extension and surgical margin status, may affect locoregional control, but their use in specifying additional indications for PMRT is currently unclear.

The risks of relapse and the effects of PMRT associated with tumour and treatment characteristics other than the number of involved axillary lymph nodes and primary tumour stage are unclear. Studies reporting associations between locoregional recurrence risk and specific factors such as patient age,, 7, histologic grade,${ }^{5,74,50}$ lymphovascular invasion, ${ }^{50-52}$ hormonal receptor status, ${ }^{53}$ surgical margin status ${ }^{40,54-56}$ number of axillary nodes removed, ${ }^{5,7,40,41,47,49,57}$ and axillary nodal extracapsular extension (ECE) ${ }^{38,58-63}$ have provided inconsistent results.

In the post-mastectomy setting, data on the effect of close or positive surgical margins on locoregional control have been particularly unclear. The available studies are limited by small samples, ${ }^{40,54-56}$ short follow-up ${ }^{54,55}$ and variable definitions of margin status ${ }^{40,54-56}$ (level $\mathrm{V}$ evidence).

The evidence for axillary dissection has been reviewed in detail in a previous guideline..$^{57}$ Although there is consensus that level I and II nodes (located lateral to and deep to the pectoralis minor muscle) should be removed for accurate staging and to reduce the risk of axillary recurrence, there is less agreement on the number of nodes that must be removed. ${ }^{57}$ In the NSABP B-04 study, the qualitative nodal status (negative versus positive) can be estimated accurately with the removal of 3 to 5 nodes. ${ }^{47}$ However, the estimate of quantitative nodal status (1 to 3 positive nodes versus 4 or more) is more reliable when at least 10 nodes are removed (level III evidence). ${ }^{47,49,57}$ With respect to axillary recurrence according to number of nodes removed, in the NSABP B04 study radical mastectomy with axillary dissection resulted in axillary recurrence rates of $3 \%$ among patients who had node-positive disease (level I evidence). ${ }^{47}$ However, in the Danish trials, the higher rates of locoregional failure among patients who had 1 to3 positive nodes have been attributed to more limited axillary surgery. ${ }^{5,7}$ Considering the lack of consistency in the available data, recommendations for PMRT in patients who have 1 to 3 positive axillary nodes and fewer than 10 nodes removed require further study. The NCIC CTG MA20 trial, which stratifies patients according to number of involved nodes and which specifies radiotherapy nodal volumes according to number of nodes removed, may provide future evidence to address this issue.

Correlations between axillary nodal ECE, recurrence risks and survival and whether ECE constitutes an indication for PMRT are also unclear. In the update of the British Columbia trial, crude overall survival rates in the nonirradiated group were poorer among patients who had ECE than among those who did not. This was not the case in the irradiated group. Among all patients who had ECE, PMRT was associated with improved overall survival (level II evidence). ${ }^{38,58}$ Several retrospective studies have demon- 
strated strong correlations between ECE and increasing numbers of positive axillary nodes (level $\mathrm{V}$ evidence). ${ }^{59-63}$ Some studies have suggested that it is associated with increased risks of chest-wall relapse rather than isolated nodal relapse $^{59,60}$ and decreased survival, ${ }^{59,61}$ while others contend that ECE alone is not a significant independent prognostic factor for relapse or survival. ${ }^{62,64}$ With the limited available data, the use of ECE, alone or in combination with other prognostic factors, in making decisions for PMRT remains to be defined.

In summary, although various patient, tumour and treatment characteristics have been suggested to be adverse prognostic factors, the use of these factors to specify clear PMRT recommendations is currently unclear.

\section{Technical considerations of radiotherapy}

- PMRT should encompass the chest wall and the supraclavicular, infraclavicular and axillary apical lymph node areas.

The evidence advising the technical aspects of PMRT is limited. Studies reporting patterns of relapse after mastectomy without radiotherapy have demonstrated that the chest wall is the most common site of locoregional relapse (50\%-75\%) (level III evidence). ${ }^{40,41,64,65}$ After axillary dissection, approximately $20 \%-40 \%$ of all locoregional relapses occurred at the supraclavicular and infraclavicular nodal regions. ${ }^{40,41,64,65}$ The radiation field used to treat the clavicular nodes generally also encompasses the axillary apex. Based on these relapse patterns, women with indications for PMRT are advised to undergo treatment encompassing the chest wall and the supraclavicular, infraclavicular and axillary apical lymph node areas (level III evidence).

- To reduce the risk of lymphedema, radiation of the entire axilla should not be used routinely after complete axillary dissection of level I and II lymph nodes.

The absolute risk of recurrence in the axilla after complete dissection of level I and II axillary lymph nodes has been estimated to be less than $5 \%$ in surgical series (level IV and V evidence). ${ }^{40,66,67}$ The number of lymph nodes removed may be used as an indicator of the extent of axillary dissection. In an analysis of trials performed by the Eastern Clinical Oncology Group, axillary recurrence decreased from $7 \%$ when 5 or fewer nodes were removed to less than $1 \%$ when 6 or more nodes were removed $(p=0.0009)$ (level III evidence). ${ }^{41}$

The risk of lymphedema is related to the extent of regional treatment with surgery and radiotherapy. ${ }^{61,68-71}$ When a single modality is used, the risk of lymphedema is approximately 5\%-10\% (level $\mathrm{V}$ evidence). ${ }^{68}$ After axillary dissection, regional radiotherapy limited to the supraclavicular and axillary apical nodes was associated with a 3\% risk of lymphedema (level $\mathrm{V}$ evidence). ${ }^{61}$ Radiotherapy to the en- tire axilla after dissection of level I and II axillary nodes, however, was demonstrated to substantially increase the risks of lymphedema, chronic arm morbidity and impaired quality of life, especially when 10 or more nodes were removed (level $\mathrm{V}$ evidence). ${ }^{69,71}$

The low rates of axillary recurrence after level I and II axillary dissection and the increased risks of lymphedema with combined nodal surgery and radiotherapy indicate that radiation of the entire axilla should not be used routinely after complete axillary dissection.

- A definite recommendation regarding the inclusion of the internal mammary lymph nodes in PMRT cannot be made because of limited and inconsistent data.

Internal mammary nodal irradiation is among the most controversial issues in breast cancer management, and the question of its use in PMRT remains unresolved. Rates of internal mammary metastasis in excess of $30 \%$ have been reported in older surgical series of women who had axillary node metastases and inner or central primary tumours (level $\mathrm{V}$ evidence). ${ }^{72}$ Other series have reported lower rates $^{73,74}$ and lesser significance of tumour location ${ }^{61}$ (level V evidence). In contrast, several randomized trials have reported low rates of clinically apparent internal mammary recurrence even in the absence of radiotherapy. ${ }^{36,75-77}$

The effect of internal mammary treatment on survival is unclear. Two randomized trials performed before the era of adjuvant systemic therapy showed no survival difference when internal mammary dissection was performed in addition to radical mastectomy. ${ }^{76,77}$ Although radiation of the internal mammary nodes was used in the Danish and British Columbia trials, its contribution to the observed radiation effect is difficult to quantify. ${ }^{5-7}$ In a trial from Finland, 270 patients who had breast-conserving therapy were randomly allocated to receive breast irradiation with or without internal mammary chain inclusion. The rates of skin reaction and radiation pneumonitis were similar in the 2 groups, but lung fibrosis was more common in the cohort receiving internal mammary treatment (level II evidence). ${ }^{78}$

The limited available data thus suggest that the rates of clinically detected relapse in the internal mammary chain are low and that the locoregional control and survival impact of specifically irradiating this region is unclear. Because of the uncertainty of benefit and the potential for increased toxicity (e.g., cardiac), recommendations for the routine incorporation of the internal mammary chain when using PMRT cannot be made.

The question of internal mammary nodal irradiation is being investigated in 2 randomized trials. The European Organization for Research and Treatment of Cancer 22922 trial randomly allocates patients who have node-positive disease or node-negative disease and medial or central tumours to receive radiation of the internal mammary and medial supraclavicular nodal area or no nodal radiation af- 
ter mastectomy or breast-conserving surgery. Although not directly applicable to the post-mastectomy setting, the Canadian NCIC CTG MA20 study may provide insight into the question of internal mammary nodal irradiation in the era of modern systemic therapy and radiotherapy planning. In this trial, patients who have high-risk disease treated with breast-conserving surgery are randomly assigned to receive standard radiotherapy to the breast, or radiotherapy to the breast and nodal regions including the ipsilateral internal mammary nodes.

- The use of modern techniques in radiotherapy planning is recommended to minimize excessive normal tissue exposure, particularly to the cardiac and pulmonary structures.

Diverse PMRT techniques have been used at different institutions. With the lack of consistent evidence on which to base recommendations on specific PMRT prescription details, general principles in delivering radiotherapy to the target and avoiding excessive exposure of normal tissue must prevail. Modern equipment with megavoltage energy, immobilization devices to ensure patient comfort and reproducibility, and planning techniques to optimize dose homogeneity and minimize radiotherapy to the cardiac and pulmonary structures should be used.79-81

The majority of studies that evaluated PMRT used $4500-5000$ cGy in 200 cGy fractions. ${ }^{19}$ Although more hypofractionated regimens have been used ${ }^{6}$ and have recently been shown to be effective after breast-conserving surgery, ${ }^{82}$ there remain concerns that the use of hypofractionated regimens for the delivery of regional nodal irradiation may increase risks of late morbidities such as lymphedema and brachial neuropathy.

\section{Adverse effects of radiotherapy}

- Common short-term side effects of PMRT, including fatigue and skin erythema, are generally tolerable and not dose-limiting. Severe long-term side effects, including lymphedema, cardiac and pulmonary toxicities, brachial plexopathy, rib fractures and secondary neoplasms, are relatively rare.

The adverse effects of radiotherapy have been detailed in a previous Canadian guideline on radiotherapy after breast-conserving surgery. ${ }^{82}$ The common side effects of fatigue and radiation dermatitis are generally transient and well-tolerated. The risks of brachial plexopathy ${ }^{83,84}$ and rib fractures $^{85}$ are estimated at less than $2 \%$ in older series and are likely even lower with modern PMRT techniques. The risk of secondary neoplasms is also rare and does not constitute a contraindication to PMRT. ${ }^{86-89}$ Lymphedema and radiation pneumonitis may occur more frequently than secondary neoplasms, and cardiac toxicity, although infrequent, is of concern.

\section{Lymphedema}

The risk of lymphedema is related to the extent of treatment of the axilla with surgery and radiotherapy ${ }^{68-71}$ This risk is less than $10 \%$ when either treatment modality is used alone ${ }^{66}$ or when axillary dissection is followed by irradiation limited to only the supraclavicular nodes and axillary apex. ${ }^{61}$ The RCTs employing full axillary irradiation after axillary dissection included the Danish study ${ }^{70}$ and the British Columbia study, ${ }^{9}$ which reported higher risks of lymphedema with PMRT (9\%-14\%) than without PMRT (3\%). Recommendations regarding the management of lymphedema have been discussed in another Canadian guideline. ${ }^{90}$

\section{Pulmonary toxicities}

Radiotherapy for breast cancer generally includes a portion of the ipsilateral lung underlying the chest wall. This is associated with a risk of clinically apparent pulmonary toxicity of less than $10 \% .{ }^{91,92}$ Tamoxifen and various chemotherapy agents have been associated with increased pulmonary side effects with PMRT. ${ }^{93-96}$ Among 1624 women treated with radiotherapy to the breast or chest wall alone or locoregional radiotherapy to the breast or chest wall plus lymph nodes, pneumonitis developed in $3 \%$ of patients treated with locoregional radiotherapy and chemotherapy compared with $0.5 \%$ in all other patients $(p=0.0001$ ) (level V evidence). ${ }^{91}$ Radiation pneumonitis occurred in $8.8 \%$ of patients receiving concurrent locoregional radiotherapy and chemotherapy, as compared with $1.3 \%$ of patients receiving sequential treatment $(p=0.002) .{ }^{91}$ In another study, symptomatic radiation pneumonitis occurred in $4.1 \%$ of patients treated with locoregional radiotherapy, as compared with $0.9 \%$ of those treated with breast or chest-wall irradiation only $(p=0.02)$ (level $\mathrm{V}$ evidence). ${ }^{92}$

\section{Cardiac toxicities}

The EBCTCG meta-analysis reported that the decrease in breast cancer mortality with radiotherapy was offset by an increase in the rate of death from other causes, predominantly cardiovascular. ${ }^{4}$ A population-based study suggested an increased risk of death from myocardial infarction associated with radiotherapy beyond 10 years of follow-up, particularly among women with left-sided breast cancer. ${ }^{97}$ Other series, however, did not demonstrate differences in cardiac toxicity according to laterality of radiotherapy. ${ }^{98,99}$

Several studies have suggested that increased cardiovascular toxicities may be related to excess radiation dose and volume to the cardiac structures. A randomized trial from Stockholm, involving 960 women treated with pre- or postoperative radiotherapy compared with mastectomy alone, reported that patients who received the highest doses to the myocardium experienced increased risks of death from ischemic heart disease (relative hazard ratio 3.2, $p<0.05$ ) (level II evidence). ${ }^{100,101}$ Hojris and colleagues ${ }^{102}$ reported no 
differences in the rates of death from ischemic heart disease and hospital admissions after 12 years of follow-up in the Danish 82b and 82c studies between patients who received radiotherapy and those who did not $(0.8 \%$ and $0.9 \%$, respectively) when techniques to limit cardiac dose and volume were used (level II evidence).

Data defining the optimal dosing and integration of potentially cardiotoxic chemotherapeutic drugs with PMRT are needed. Observations of enhanced cardiac toxicities have been reported among patients treated with high-dose anthracycline-based regimens of $450 \mathrm{mg} / \mathrm{m}^{2}$ and irradiation, ${ }^{43}$ whereas modest ${ }^{44}$ to no excess risks ${ }^{45}$ were found when lower anthracycline doses were used with radiotherapy.

\section{Sequencing of radiotherapy and systemic therapy}

- The optimal sequencing of PMRT and systemic therapy is currently unclear. Regimens containing anthracyclines or taxanes should not be administered concurrently with radiotherapy because of the potential for increased toxicity.

The options in scheduling PMRT and chemotherapy include: sequential (delivery of radiotherapy after completion of all chemotherapy or before the initiation of chemotherapy); concurrent (delivery of radiotherapy at the same time as chemotherapy); or "sandwich" (delivery of chemotherapy before and after radiotherapy). There are little data from randomized clinical trials to address this issue. A variety of approaches to scheduling were used in the trials of PMRT. ${ }^{19}$ The single randomized trial directly addressing treatment sequencing showed no survival difference when chemotherapy was delivered before or after radiotherapy among patients treated with breast-conserving surgery (level II evidence). ${ }^{103,104}$

With the lack of data showing clear differences in locoregional control or survival favouring one scheduling approach over another, issues regarding treatment toxicities must also be considered. In the trial comparing anthracycline-based chemotherapy before or after radiotherapy following breast-conserving surgery, sequential chemotherapy and radiotherapy did not adversely affect the risks of cardiac toxicity, cellulitis, arm edema or brachial plexopathy at a median follow-up of 53 months (level II evidence). ${ }^{103}$

Several retrospective series have implicated the anthracyclines and taxanes as drugs associated with increased risks of toxicities to normal structures, including the skin, soft tissues, lung and heart, when delivered concurrently with radiotherapy (level $\mathrm{V}$ evidence). ${ }^{46,93,94}$

The optimal sequencing of PMRT and adjuvant endocrine therapy is also unclear. A retrospective analysis of 84 postmenopausal women treated in the prospective randomized Danish study suggested a higher risk of pulmonary fibrosis among women who received concurrent tamoxifen and PMRT than among women who did not receive tamoxifen (OR 2.9, $p=0.007$ ) (level V evidence). ${ }^{95}$ Another study reported pulmonary fibrosis in 26 of 74 patients treated with concurrent tamoxifen and PMRT, as compared with 5 of 37 patients treated with PMRT alone $(p=0.01$ ) (level V evidence). ${ }^{96}$ The authors hypothesized that tamoxifen may enhance radiation fibrosis by inducing transforming growth factor-beta secretion..$^{95,96}$

In summary, the optimal sequencing of PMRT with systemic therapy remains to be defined. Many centres favour the administration of systemic chemotherapy before locoregional radiotherapy ${ }^{82}$ Concurrent delivery of PMRT in patients receiving anthracycline- or taxane-based regimens is not recommended because of the potential for increased toxicity.

The risks of severe long-term toxicities with PMRT are relatively small but may be increased by excessive radiation dose and volume to the normal structures and by specific systemic agents. These findings support the use of modern techniques in radiation planning to minimize normal tissue exposure $^{79-81}$ and attention to scheduling of chemotherapy and radiotherapy.

\section{This article has been peer reviewed.}

Dr. Truong is with the BC Cancer Agency-Vancouver Island Centre and is Clinical Assistant Professor in the Department of Surgery, University of British Columbia, Victoria, BC; Dr. Olivotto is with the BC Cancer Agency-Vancouver Island Centre and is Clinical Professor in the Department of Surgery, University of British Columbia, Victoria, BC; Dr. Whelan is with Cancer Care Ontario Hamilton Regional Cancer Centre and is Associate Professor in the Department of Medicine, McMaster University, Hamilton, Ont.; Dr. Levine is Professor in the Departments of Clinical Epidemiology and Biostatistics and of Medicine and is the Buffet Taylor Chair in Breast Cancer Research, McMaster University, Hamilton, Ont.

Competing interests: None declared.

Contributors: All of the authors contributed substantially to the review of the literature and to the writing of this guideline, and all have given final approval of the version to be published.

Acknowledgements: We thank the following oncologists for their valuable advice: Dr. Ida Ackerman (Toronto-Sunnybrook Regional Cancer Centre, Toronto, Ont.); Dr. Susan Chafe (Cross Cancer Institute, Edmonton, Alta.); Dr. Carolyn Freeman (McGill University Health Centre, Montreal, Que.); Dr. Francisco Perera (London Regional Cancer Centre, London, Ont.); Dr. Jean-Phillipe Pignol (Toronto-Sunnybrook Regional Cancer Centre, Toronto, Ont.); Dr. Joseph Ragaz (McGill University Health Centre, Montreal, Que.); Dr. Dorianne Rheaume (Nova Scotia Cancer Centre, Halifax, NS); Dr. Pierre Rousseau (CHUM-Hôpital Notre-Dame, Montreal, Que.); Dr. Jonathan Sussman (Hamilton Regional Cancer Centre, Hamilton, Ont.); Dr. Katherine Vallis (Princess Margaret Hospital, Toronto, Ont.); and Dr. Lorna Weir (BC Cancer Agency-Vancouver Centre, Vancouver, BC).

The Steering Committee is part of Health Canada's Canadian Breast Cancer Initiative.

\section{References}

1. Cuzick J, Stewart H, Peto R, Baum M, Fisher B, Host H, et al. Overview of randomized trials of postoperative adjuvant radiotherapy in breast cancer. Cancer Treat Rep 1987;71:15-29.

2. Cuzick J, Stewart H, Rutqvist L, Houghton J, Edwards R, Redmond C, et al. Cause-specific mortality in long-term survivors of breast cancer who participated in trials of radiotherapy. $\mathcal{F}$ Clin Oncol 1994;12:447-53.

3. Early Breast Cancer Trialists' Collaborative Group: Effects of radiotherapy and surgery in early breast cancer: an overview of the randomized trials. $N$ Engl 7 Med 1995;333:1444-55.

4. Early Breast Cancer Trialists' Collaborative Group: Favourable and unfavourable effects on long-term survival of radiotherapy for early breast cancer: an overview of the randomised trials. Lancet 2000;355:1757-70.

5. Overgaard M, Hansen PS, Overgaard J, Rose C, Andersson M, Bach F, et al. Postoperative radiotherapy in high-risk premenopausal women with breast cancer who receive adjuvant chemotherapy. Danish Breast Cancer Cooperative Group 82b Trial. N Engl 7 Med 1997;337:949-55.

6. Ragaz J, Jackson SM, Le N, Plenderleith IH, Spinelli JJ, Basco VE, et al. Ad- 
juvant radiotherapy and chemotherapy in node-positive premenopausal women with breast cancer. N Engl 7 Med 1997;337:956-62.

7. Overgaard M, Jensen MB, Overgaard J, Hansen PS, Rose C, Andersson M, et al. Postoperative radiotherapy in high-risk postmenopausal breast cancer patients given adjuvant tamoxifen: Danish Breast Cancer Cooperative Group (DBCG) 82c randomised trial. Lancet 1999;353:1641-8.

8. Early Breast Cancer Trialists' Collaborative Group: Systemic treatment of early breast cancer by hormonal, cytotoxic or immune therapy: 133 randomised trials involving 31000 recurrences and 24000 deaths among 75000 women. Lancet 1992;339:1-15,71-85.

9. Early Breast Cancer Trialists' Collaborative Group: Tamoxifen for early breast cancer: an overview of the randomised trials. Lancet 1998;351:1451-67.

10. Recht A, Edge SB, Solin LJ, Robinson DS, Estabrook A, Fine RE, et al. Postmastectomy radiotherapy: guidelines of the American Society of Clinical Oncology. 7 Clin Oncol 2001;19:1539-69.

11. Hellman S. Stopping metastases at their source. N Engl 7 Med 1997;337:996-7.

12. Recht A, Bartelink H, Fourquet A, Fowble B, Haffty BG, Harris JR, et al. Postmastectomy radiotherapy: questions for the twenty-first century. 7 Clin Oncol 1998; 16:2886-9.

13. Harris JR, Halpin-Murphy P, McNeese M, Mendenhall NP, Morrow M, Robert NJ. Consensus statement on postmastectomy radiation therapy. Int $\mathcal{F}$ Radiat Oncol Biol Phys 1999;44:989-90.

14. Taylor ME, Haffty BG, Shank BM, Halberg FE, Martinez AA, McCormick $\mathrm{B}$, et al. Postmastectomy radiotherapy. American College of Radiology. ACR Appropriateness Criteria. Radiology 2000;215 Suppl:1153-70.

15. Pierce LJ. Treatment guidelines and techniques in delivery of postmastectomy radiotherapy in management of operable breast cancer. 7 Natl Cancer Inst Monogr 2001;30:117-24

16. Eifel P, Axelson JA, Costa J, Crowley J, Curran WJ Jr, Deshler A, et al. National Institutes of Health Consensus Development Statement: adjuvant therapy for breast cancer, November 1-3,2000.7 Natl Cancer Inst 2001:93:979-89.

17. Sackett DL. Rules of evidence and clinical recommendations on the use of antithrombotic agents. Chest 1989;95 (Suppl):2S-4S.

18. Steering Committee on Clinical Practice Guidelines for the Care and Treatment of Breast Cancer. Clinical practice guidelines for the care and treatment of breast cancer. CMA7 1998;158(3 Suppl):S1-83

19. Whelan TJ, Julian J, Wright J, Jadad AR, Levine ML. Does locoregional radiotherapy improve survival in breast cancer? A meta-analysis. 7 Clin Oncol 2000;18:1220-9.

20. Grohn P, Heinonen E, Klefstrom P, Tarkkanen J. Adjuvant postoperative radiotherapy, chemotherapy, and immunotherapy in stage III breast cancer. Cancer 1984;54:670-4.

21. Klefstrom P, Grohn P, Heinonen E, Holsti L, Holsti P. Adjuvant postoperative radiotherapy, chemotherapy, and immunotherapy in stage III breast cancer: II. 5-year results and influence of levamisole. Cancer 1987;60:936-42.

22. Blomqvist C, Tiusanen K, Elomaa I, Rissanen P, Hietanen T, Heinonen E, et al. The combination of radiotherapy, adjuvant chemotherapy (cyclophosphamide-doxorubicin-ftorafur) and tamoxifen in stage II breast cancer: Longterm follow-up results of a randomised trial. Br 7 Cancer 1992;66:1171-6.

23. Hayat H, Brufman G, Borovik R, Chaichick S, Rath P, Robinson E, et al. Adjuvant chemotherapy and radiation therapy vs. chemotherapy alone for stage II breast cancer patients. A national randomized trial [abstract]. Ann Oncol 1990;1(Suppl):21.

24. Gervasio H, Alves H, Rito A, Albano J. Phase III study: adjuvant chemotherapy versus radiotherapy plus chemotherapy in women with node-positive breast cancer. A retrospective analysis of 18 years [abstract]. Breast 7 1998;4(Suppl 1):S88.

25. Cooper MR, Rhyne AL, Muss HB, Ferree C, Richards F II, White DR, et al. A randomized comparative trial of chemotherapy and irradiation therapy for stage II breast cancer. Cancer 1981;47:2833-9.

26. Muss HB, Cooper MR, Brockschmidt JK, Ferree C, Richards F II, White $\mathrm{DR}$, et al. A randomized trial of chemotherapy (L-PAM vs CMF) and irradiation for node-positive breast cancer. Eleven year follow-up of a Piedmont Oncology Association trial. Breast Cancer Res Treat 1991;19:77-84.

27. Schmoor C, Bastert G, Dunst J, Bojar H, Christmann D, Unbehaun V, et al. Randomized trial on the effect of radiotherapy in addition to 6 cycles of $\mathrm{CMF}$ in node-positive breast-cancer patients. The German Breast-Cancer Study Group. Int 7 Cancer 2000;86:408-15.

28. Griem KL, Henderson IC, Gelman R, Ascoli D, Silver B, Recht A, et al. The 5 -year results of a randomized trial of adjuvant radiation therapy after chemotherapy in breast cancer patients treated with mastectomy. 7 Clin Oncol 1987;5:1546-55.

29. McArdle CS, Crawford D, Dykes EH, Calman KC, Hole D, Russell AR, et al. Adjuvant radiotherapy and chemotherapy in breast cancer. Br 7 Surg 1986;73:264-6.

30. Vélez-Garcia E, Carpenter JT, Moore M, Vogel CL, Marcial V, Ketcham A, et al. Postsurgical adjuvant chemotherapy with or without radiotherapy in women with breast cancer and positive axillary nodes: a South-Eastern Cancer Study Group (SEG) Trial. Eur 7 Cancer 1992;28A:1833-7.

31. Ahmann DL, O'Fallon JR, Scanlon PW, Payne WS, Biset HF, Edmonson $\mathrm{JH}$, et al. A preliminary assessment of factors associated with recurrent disease in a surgical adjuvant clinical trial for patients with breast cancer with special emphasis on the aggressiveness of therapy. Am f Clin Oncol 1982;5:371-81.

32. Martinez A, Ahmann DL, O'Fallon J, Payne W, Scanlon P, Hahn R. An interim analysis of the randomized surgical adjuvant trial for patients with unfavorable breast cancer [abstract]. Int 7 Radiat Oncol Biol Phys 1984;10(Suppl 2): 106 .

33. Olson JE, Neuberg D, Pandya KJ, Richter MP, Solin LJ, Gilchrist KW, et al The role of radiotherapy in the management of operable locally advanced breast carcinoma: results of a randomized trial by the Eastern Cooperative Oncology Group. Cancer 1997;79:1138-49.

34. Arwidi A, Aspegren K, Augustsson NE, Hafstrom L, Norgren A, Svahn-Tapper G. Postoperative radiation therapy in mammary carcinoma stage II. Target volume, organs at risk, absorbed dose, time-dose schedule and dose to organs at risk in a prospective investigation. Acta Radiol Oncol Radiat Phys Biol 1979;18:273-81.

35. Ryden S, Ferno M, Moller T, Aspergren K, BergljungL, Killander D, et al. Long-term effects of adjuvant tamoxifen and/or radiotherapy. The South Sweden Breast Cancer Trial. Acta Oncol 1992;31:271-4.

36. Tennvall-Nittby L, Tengrup I, Landberg T. The total incidence of loco-regional recurrence in a randomized trial of breast cancer TNM stage II. The South Sweden Breast Cancer Trial. Acta Oncol 1993;32:641-6.

37. Mouridsen HT, Rose C, Overgaard M, Dombernowsky P, Panduro J, Thorpe S, et al. Adjuvant treatment of postmenopausal patients with high risk primary breast cancer: results from the Danish adjuvant trials DBCG 77C and DBCG 82C. Acta Oncol 1988;27:699-705.

38. Ragaz J, Jackson S, Le N, Manji M, Wilson K, Olivotto I, et al. Postmastectomy radiation (RT) outcome in node $(\mathrm{N})$ positive breast cancer patients among N1-3 versus N4+ subset: impact of extracapsular spread (ES). Update of the British Columbia randomized trial [abstract]. Proc Am Soc Clin Oncol 1999;32:73a.

39. Katz A, Strom EA, Bucholz TA, Theriault R, Singletary SE, McNeese MD The influence of pathologic tumor characteristics on locoregional recurrence rates following mastectomy. Int 7 Radiat Oncol Biol Phys 2001;50:735-742.

40. Katz A, Strom EA, Buchholz TA, Thames HD, Smith CD, Jhingran A, et al Locoregional recurrence patterns after mastectomy and doxorubicin-based chemotherapy: implications for postoperative irradiation $.7 \mathrm{Clin}$ Oncol 2000;18:2817-27.

41. Recht A, Gray R, Davidson NE, Fowble BL, Solin LJ, Cummings FJ, et al. Locoregional failure 10 years after mastectomy and adjuvant chemotherapy with or without tamoxifen without irradiation: experience of the Eastern Cooperative Oncology Group. 7 Clin Oncol 1999;17:1689-700.

42. Levine M. Clinical practice guidelines for the care and treatment of breast cancer: adjuvant systemic therapy for node-positive breast cancer (summary of the 2001 update). The Steering Committee on Clinical Practice Guidelines for the Care and Treatment of Breast Cancer. CMA7 2001;164(5):644-6.

43. Shapiro CL, Hardenbergh PH, Gelman R, Blanks D, Hauptman P, Recht A et al. Cardiac effects of adjuvant doxorubicin and radiation therapy in breast cancer patients. 7 Clin Oncol 1998;16:3493-501.

44. Zambetti M, Moliterni A, Materzazzo C, Stefanelli M, Cipriani S, Valagussa $\mathrm{P}$, et al. Long-term cardiac sequelae in operable breast cancer patients given adjuvant chemotherapy with or without doxorubicin and breast irradiation. 7 Clin Oncol 2001;19:37-43.

45. Hardenbergh P, Recht A, Gollamudi S, Come SE, Hayes DF, Shulman LN et al. Treatment-related toxicity from a randomized trial of the sequencing of doxorubicin and radiation therapy in patients treated for early stage breast cancer. Int 7 Radiat Oncol Biol Phys 1999;45:69-72.

46. Formenti SC, Symmans WF, Volm M, Skinner K, Cohen D, Spicer D, et al. Concurrent paclitaxel and radiation therapy for breast cancer. Semin Radiat Oncol 1999;9(2 Suppl 1):34-42.

47. Fisher B, Redmond C, Fisher ER, Bauer M, Wolmark N, Wickerham LD, et al. Ten-year results of a randomized clinical trial comparing radical mastectomy and total mastectomy with or without radiation. $N$ Engl $7 \mathrm{Med}$ 1985;312:674-81.

48. Fisher B, Jeong JH, Anderson S, Bryant J, Fisher ER, Wolmark N. Twentyfive-year follow-up of a randomized trial comparing radical mastectomy, total mastectomy and total mastectomy followed by irradiation. $N$ Engl $7 \mathrm{Med}$ 2002;347:567-575

49. Axelsson CK, Mouridsen HT, Zedeler K. Axillary dissection for level I and II lymph nodes is important in breast cancer classification. The Danish Breast Cancer Cooperative Group (DBCG). Eur 7 Cancer 1992;28A:1415-8.

50. Morgan DA, Berridge J, Blamey RW. Postoperative radiotherapy following mastectomy for high-risk breast cancer. A randomised trial. Eur 7 Cancer 2002;38:1107-10.

51. Wallgren A, Bonetti M, Gelber RD, Goldhirsch A, Castiglione-Gertsch M Holmberg SB, et al. Risk factors for locoregional recurrence among breas cancer patients: results from International Breast Cancer Study Group Trials I Through VII. 7 Clin Oncol 2003;21:1205-13.

52. O'Rourke S, Galea MH, Morgan D, Euhus D, Pinder S, Ellis IO, et al. Local recurrence after simple mastectomy. Br 7 Surg 1994;81:386-9.

53. Pisansky TM, Ingle JN, Schaid DJ, Hass AC, Krook JE, Donohue JH, et al Patterns of tumor relapse following mastectomy and adjuvant systemic therapy in patients with axillary lymph node-positive breast cancer. Impact of clinical, histopathologic, and flow cytometric factors. Cancer 1993;72:1247-60.

54. Mentzer SJ, Osteen RT, Wilson RE. Local recurrence and the deep resection 
margin in carcinoma of the breast. Surg Gynecol Obstet 1986;163:513-7.

55. Ahlborn TN, Gump FE, Bodian C, Habif DV, Kister S. Tumor to fascia margin as a factor in local recurrence after modified radical mastectomy. Surg Gynecol Obstet 1988;166:523-6.

56. Freedman GM, Fowble BL, Hanlon AL, Myint MA, Hoffman JP, Sigurdson $\mathrm{ER}$, et al. A close or positive margin after mastectomy is not an indication for chest wall irradiation except in women aged fifty or younger. Int 7 Radiat Oncol Biol Phys 1998;41:599-605.

57. Clinical practice guidelines for the care and treatment of breast cancer: axillary dissection. Steering Committee on Clinical Practice Guidelines for the Care and Treatment of Breast Cancer. CMA7 1998;158(3 Suppl):S22-S26.

58. Ragaz J, Jackson S, Le N, Spinelli J, Coldman A, Wilson K, et al. Survival gains of locoregional radiation (RT) in breast cancer with 1-3 positive axillary nodes (N1-3): locoregional recurrences (LocRecs) are NOT a useful guide to predict the benefit of the RT - an update from the British Columbia (BC) randomized trial [abstract]. Proc Am Soc Clin Oncol 2000;19:82a.

59. Leonard C, Corkill M, Tompkin J, Zhen B, Waitz D, Norton L, et al. Are axillary recurrence and overall survival affected by axillary extranodal tumor extension in breast cancer? Implications for radiation therapy. $\mathcal{f}$ Clin Oncol 1995;13:47-53.

60. Mignano JE, Zahurak ML, Chakravarthy A, Piantadosi S, Dooley WC, Gage I. Significance of axillary lymph node extranodal soft tissue extension and indications for postmastectomy irradiation. Cancer 1999;86:1258-62.

61. Pierce LJ, Oberman HA, Strawderman MH, Lichter AS. Microscopic extracapsular extension in the axilla: is this an indication for axillary radiotherapy? Int 7 Radiat Oncol Biol Phys 1995;33:253-9.

62. Donegan WL, Stine SB, Samter TG. Implications of extracapsular nodal metastases for treatment and prognosis of breast cancer. Cancer 1993;72:778-82.

63. Fisher BJ, Perera FE, Cooke AL, Opeitum A, Dar AR, Venkatesan VM, et al. Extracapsular axillary node extension in patients receiving adjuvant systemic therapy: an indication for radiotherapy? Int 7 Radiat Oncol Biol Phys 1997;38:551-9.

64. Halverson KJ, Perez CA, Kuske RR, Garcia DM, Simpson JR, Fineberg B. Isolated local-regional recurrence of breast cancer following mastectomy: radiotherapeutic management. Int 7 Radiat Oncol Biol Phys 1990;19:851-8.

65. Schwaibold F, Fowble BL, Solin LJ, Schultz DJ, Goodman RL. The results of radiation therapy for isolated local regional recurrences after mastectomy. Int 7 Radiat Oncol Biol Phys 1991;21:299-310.

66. Fowble B, Solin LJ, Schultz DJ, Goodman RL. Frequency, sites of relapse, and outcome of regional node failures following conservative surgery and radiation for early breast cancer. Int 7 Radiat Oncol Biol Phys 1989;17:703-10.

67. Recht A, Pierce SM, Abner A, Vicini F, Osteen RT, Love SM, et al. Regiona nodal failure after conservative surgery and radiotherapy for early stage breast carcinoma. 7 Clin Oncol 1991;9:988-96.

68. Kissin MW, Querci della Rovere G, Easton D, Westbury G. Risk of lymphoedema following the treatment of breast cancer. Br 7 Surg 1986;73:580-4.

69. Kwan W, Jackson J, Weir LM, Dingee C, McGregor G, Olivotto IA Chronic arm morbidity after curative breast cancer treatment: prevalence and impact on quality of life. 7 Clin Oncol 2002;20:4242-8.

70. Hojris I, Andersen J, Overgaard M, Overgaard J. Late treatment-related morbidity in breast cancer patients randomized to postmastectomy radiotherapy and systemic treatment versus systemic treatment alone. Acta Oncol 2000;39:355-72.

71. Larson D, Weinstein M, Goldberg I, Silver B, Recht A, Cady B, et al. Edema of the arm as a function of the extent of axillary surgery in patients with stage I-II carcinoma of the breast treated with primary radiotherapy. Int 7 Radiat Oncol Biol Phys 1986;12:1575-82

72. Urban JA, Marjani MA. Significance of internal mammary lymph node metastases in breast cancer. Am 7 Roentgenol Radium Ther Nucl Med 1971;111:130-6.

73. Veronesi U, Cascinelli N, Greco M, Bufalino R, Morabito A, Galluzzo D, et al. Prognosis of breast cancer patients after mastectomy and dissection of internal mammary nodes. Ann Surg 1985;202:702-7.

74. Noguchi M, Ohta N, Thomas M, Kitagawa H, Myiazaki I. Risk of interna mammary lymph node metastases and its prognostic value in breast cancer patients. 7 Surg Oncol 1993;52:26-30.

75. Lacour J, Bucalossi P, Cacers E, Jacobelli G, Koszarowski T, Le M, et al. Radical mastectomy versus radical mastectomy plus internal mammary dissection. Five-year results of an international cooperative study. Cancer 1976;37:206-14.

76. Lacour J, Le M, Caceres E, Koszarowski T, Veronesi U, Hill C. Radical mastectomy versus radical mastectomy plus internal mammary dissection. Ten year results of an international cooperative trial in breast cancer. Cancer 1983;51:1941-3.

77. Veronesi U, Marubini E, Mariani L, Valagussa P, Zucali R. The dissection of internal mammary nodes does not improve the survival of breast cancer patients: 30-year results of a randomised trial. Eur 7 Cancer 1999;35:1320-5.

78. Kaija H, Maunu P. Tangential breast irradiation with or without internal mammary chain irradiation: results of a randomized trial. Radiother Oncol 1995;36:172-6.

79. Marks LB, Hebert ME, Bentel G, Spencer DP, Sherouse GW, Prosnitz LR. To treat or not to treat the internal mammary nodes: a possible compromise. Int 7 Radiat Oncol Biol Phys 1994;29:903-9.
80. Hurkmans CW, Cho BC, Damen E, Zijp L, Mijnheer BJ. Reduction of cardiac and lung complication probabilities after breast irradiation using conformal radiotherapy with or without intensity modulation. Radiotber Oncol 2002;62:163-71.

81. Pierce LJ, Butler JB, Martel MK, Normolle DP, Koelling T, Marsh RB, et al. Postmastectomy radiotherapy of the chest wall: dosimetric comparison of common techniques. Int 7 Radiat Oncol Biol Phys 2002;52:1220-30.

82. Whelan T, Olivotto I, Levine M. Clinical practice guidelines for the care and treatment of breast cancer: 6 . Breast radiotherapy after breast-conserving surgery (2003 update). CMA7 2003;168(4):437-9.

83. Olsen NK, Pfeiffer P, Johanssen L, Schroder H, Rose C. Radiation-induced brachial plexopathy: neurological follow-up in 161 recurrence-free breast cancer patients. Int 7 Radiat Biol Pbys 1993;26:43-9.

84. Powell S, Cooke J, Parsons C. Radiation-induced brachial plexus injury: followup of two different fractionation schedules. Radiother Oncol 1990;18:213-20.

85. Pierce SM, Recht A, Lingos T, Abner A, Vicini F, Silver B, et al. Long-term radiation complications following conservative surgery (CS) and radiation therapy (RT) in patients with breast cancer. Int $\mathcal{F}$ Radiat Biol Phys 1992;23:915-23.

86. Huang J, Mackillop WJ. Increased risk of soft tissue sarcoma after radiotherapy in women with breast carcinoma. Cancer 2001;92:172-80.

87. Boice JD, Harvey EB, Blettner M, Stovall M, Flannery JT. Cancer in the contralateral breast after radiotherapy for breast cancer. $N$ Engl $7 \mathrm{Med}$ 1992;326:781-5.

88. Curtis RE, Boice JD Jr, Stovall M, Bernstein L, Greenberg RS, Flannery JT, et al. Risk of leukemia after chemotherapy and radiation treatment for breast cancer. N Engl 7 Med 1992; 326:1745-51.

89. Smith RE, Bryant J, DeCillis A, Anderson A. Acute myeloid leukemia and myelodysplastic syndrome following doxorubicin-cyclophosphamide adjuvant therapy for operable breast cancer: the NSABP experience. Breast Cancer Res Treat 2001;69:209

90. Harris SR, Hugi MR, Olivotto IA, Levine M, and the Steering Committee for Clinical Practice Guidelines for the Care and Treatment of Breast Cancer. Clinical practice guidelines for the care and treatment of breast cancer: 11. Lymphedema. CMA7 2001;164(2):191-9.

91. Lingos TI, Recht A, Vicini F, Abner A, Silver B, Harris JR. Radiation pneumonitis in breast cancer patients treated with conservative surgery and radiation therapy. Int 7 Radiat Oncol Biol Pbys 1991;21:355-60.

92. Lind PA, Marks LB, Hardenbergh PH, Clough R, Fan M, Hollis D, et al. Technical factors associated with radiation pneumonitis after local +/- regional radiation therapy for breast cancer. Int 7 Radiat Oncol Biol Phys 2002;52:137-43

93. Taghian AG, Assaad SI, Niemierko A, Kuter I, Younger J, Schoenthaler R, et al. Risk of pneumonitis in breast cancer patients treated with radiation therapy and combination chemotherapy with paclitaxel. 7 Natl Cancer Inst 2001;93:1806-11.

94. Hanna YM, Baglan KL, Stromberg JS, Vicini FA, A Decker D. Acute and subacute toxicity associated with concurrent adjuvant radiation therapy and paclitaxel in primary breast cancer therapy. Breast 7 2002;8:149-53.

95. Bentzen SM, Skoczylas JZ, Overgaard M, Overgaard J. Radiotherapy-related lung fibrosis enhanced by tamoxifen. 7 Natl Cancer Inst 1996;88:918-22.

96. Koc M, Polat P, Suma S. Effects of tamoxifen on pulmonary fibrosis after cobalt-60 radiotherapy in breast cancer patients. Radiother Oncol 2002;64:171-5.

97. Paszat LF, Mackillop WJ, Groome PA, Boyd C, Schulze K, Holowaty E. Mortality from myocardial infarction after adjuvant radiotherapy for breast cancer in the surveillance, epidemiology and end results cancer registries. $\mathcal{F}$ Clin Oncol 1998;16:2625-31.

98. Nixon AJ, Manola J, Gelman R, Bornstein B, Abner A, Hetelekidis S, et al. No long-term increase in cardiac-related mortality after breast-conserving surgery and radiation therapy using modern techniques. 7 Clin Oncol 1998;16:1374-9.

99. Vallis KA, Pintilie M, Chong N, Holowaty E, Douglas PS, Kirkbride P, et al. Assessment of coronary heart disease morbidity and mortality after radiation therapy for early breast cancer. 7 Clin Oncol 2002;20:1036-42.

100. Rutqvist LE, Lax I, Fornander T, Johansson H. Cardiovascular mortality in a randomized trial of adjuvant radiation versus surgery alone in primary breast cancer. Int 7 Radiat Oncol Biol Phys 1992;22:887-96.

101. Gyenes G, Rutqvist LE, Liedberg A, Fornander T. Long-term cardiac morbidity and mortality in a randomized trial of pre- and postoperative radiation therapy versus surgery alone in primary breast cancer. Radiother Oncol 1998;48:185-190.

102. Hojris I, Overgaard M, Christensen JJ, Overgaard J. Morbidity and mortality of ischaemic heart disease in high-risk breast-cancer patients after adjuvant postmastectomy systemic treatment with or without radiotherapy: analysis of DBCG $82 \mathrm{~b}$ and 82c randomised trials. Lancet 1999;354:1425-30.

103. Recht A, Come SE, Henderson IC, Gelman RS, Silver B, Hayes DF, et al. The sequencing of chemotherapy and radiation therapy after conservative surgery for early-stage breast cancer. N Engl 7 Med 1996;334:1356-61.

104. Bellon JR, Come SE, Gelman RS, Henderson IC, Shulman LN, Silver B, et al. Sequencing of chemotherapy and radiation therapy for patients with early stage breast cancer: updated results of a prospective randomized trial. Int 7 Radiat Oncol Biol Phys 2001;51(Suppl 1):2. 
Members of the Steering Committee on Clinical Practice Guidelines for the Care and Treatment of Breast Cancer Chair: Dr. Mark Levine (Cancer Care Ontario), Hamilton Regional Cancer Centre and McMaster University, Hamilton, Ont. Members: Dr. Penny Barnes, Queen Elizabeth II Health Sciences Centre, Halifax, NS; Dr. Judy Caines (Federal/Provincial/Territorial Advisory Committee on Health Services), Nova Scotia Cancer Centre, Halifax, NS; Dr. Jacques Cantin (deceased) (Royal College of Physicians and Surgeons of Canada), Centre hospitalier de I'Université de Montréal, Montreal, Que.; Dr. Beverley Carter, St. John's, Nfld.; Dr. Eva Grunfeld (College of Family Physicians of Canada), Ottawa Regional Cancer Centre, Ottawa, Ont.; Ms. Sabina Mallard (Canadian Breast Cancer Network), consumer representative, Stratford, PEI; Dr. Mohamed Mohamed (Saskatchewan Cancer Foundation), Saskatoon Cancer Centre,
Saskatoon, Sask.; Dr. Ivo A. Olivotto (BC Cancer Agency), Vancouver Island Cancer Centre and University of British Columbia, Victoria, BC; Dr. Leonard Reyno (Cancer Care Nova Scotia), Nova Scotia Cancer Centre, Halifax, NS; Dr. Carol Sawka (Cancer Care Ontario), Toronto Sunnybrook Regional Cancer Centre, Toronto, Ont.; Dr. Hugh Scarth (Atlantic Health Sciences Corporation), Saint John Regional Hospital, Saint John, NB; and Dr. Timothy Whelan (Cancer Care Ontario), Hamilton Regional Cancer Centre and McMaster University, Hamilton, Ont.

Correspondence to: Dr. Mark Levine, Rm. 104, Henderson Research Centre, Henderson Hospital, 711 Concession St., Hamilton ON L8V 1C3; fax 905 389-9288

\section{Appendix 1 \\ Questions and answers on radiotherapy after mastectomy}

\section{A guide for women and their physicians}

\section{What is mastectomy?}

Mastectomy is an operation that removes the whole breast. This is the type of surgery that you have undergone.

\section{What is radiotherapy?}

Radiotherapy or radiation therapy is the use of high-energy x-rays to kill cancer cells. Depending on several factors, including where cancer cells have been found in the region of your breast, your medical specialists may recommend this treatment.

\section{What is post-mastectomy radiotherapy?}

Post-mastectomy radiotherapy or PMRT is the term used for radiation applied, after mastectomy, to the locoregional areas (i.e., chest wall, armpit region and lymph nodes above your collarbone). The aim of this treatment is to stop the cancer from returning to these regions. Doctors refer to the reappearance of cancer in these regions as locoregional recurrence.

\section{Will I be offered PMRT?}

Before deciding whether to offer you PMRT, your medical specialists will need to consider the risk of locoregional recurrence and whether PMRT is likely to prevent it. Studies have found that PMRT helps women who have cancer in 4 or more lymph nodes in the armpit. It is unclear, though, whether PMRT helps women who have cancer in only 1 to 3 lymph nodes in the armpit. Researchers are also looking at other factors, including the number of nodes removed from the armpit during surgery and the presence of cancer cells in the tissue near the surgical incision, to see if these factors will help to predict when PMRT should be offered; however, they have not reached a conclusion. PMRT is also often used when the tumour is large (for example, greater than $5 \mathrm{~cm}$ in diameter) or when the tumour invades the skin or chest wall.

\section{Will I be offered other treatment in addition to PMRT?}

You may also be offered treatment with anticancer drugs (chemotherapy or hormonal therapy, or both). For more information about chemotherapy and hormonal therapy see guideline 8 (available at www.cmaj.ca/cgi/content/full/158/3/DC1).

\section{Is there a "best" treatment schedule for PMRT and chemotherapy?}

There are 3 options for scheduling:

- Sequential treatment: chemotherapy first followed by radiotherapy, or radiotherapy first followed by chemotherapy.

- Concurrent treatment: chemotherapy and radiotherapy given at the same time.

- "Sandwich" treatment: chemotherapy given before and again after radiotherapy.

We do not have enough information yet to say whether one of these options is better than another. In many centres, PMRT is administered after chemotherapy. However, we do know that concurrent scheduling with chemotherapy based on anthracyclines (anticancer agents such as doxorubicin and epirubicin) or taxanes (anticancer agents such as paclitaxel and docetaxel) can lead to more side effects. For this reason, concurrent radiotherapy and chemotherapy using these anticancer drugs is not recommended.

\section{What are the possible side effects of PMRT?}

PMRT commonly causes some mild, short-term side effects, such as tiredness and reddening of the skin. In rare cases, PMRT can also cause more serious, long-term side effects. These include lymphedema (swelling of the arm), pneumonitis (inflammation of lung tissue), cardiac injury (heart problems), brachial plexopathy (nerve problems in the arm, chest and shoulder), broken ribs and new cancers elsewhere in the body. 